\title{
CULTURA DO MEDO E JUSTIÇA RESTAURATIVA: O PAPEL DOS MEIOS ALTERNATIVOS DE RESOLUÇÃO DE CONFLITOS NO ÂMBITO PENAL NA CONSTRUÇÃO DE UMA SOCIEDADE DEMOCRÁTICA
}

\author{
Cláudio Daniel de Souza* \\ Daniel Achutti**
}

\begin{abstract}
RESUMO: O presente trabalho tem como objetivo o estudo da cultura do medo e suas consequências no âmbito penal. A problematização do tema se dá a partir da abordagem dos meios alternativos de resolução de conflitos na seara penal, com o intuito de demonstrar o quanto a justiça restaurativa, como meio alternativo ao sistema de justiça criminal tradicional, pode contribuir para a minimização dos efeitos do medo contemporâneo.
\end{abstract}

Palavras-Chave: Sistema Penal; Punição; Medo; Mídia; Justiça Restaurativa.

\section{CULTURE OF FEAR AND RESTORATIVE JUSTICE: THE ROLE OF ALTERNATIVE MEANS OF CONFLICTS RESOLUTION AT THE SCOPE OF CRIMINAL LAW IN THE CONSTRUCTION OF A DEMOCRATIC SOCIETY}

\begin{abstract}
This paper aims to study the culture of fear and its consequences in the criminal law scope. The problematization of this theme comes from the approach of alternative means of conflict resolution in the criminal law system, in order to demonstrate how restorative justice, as an alternative mean to the traditional criminal justice, can contribute to the minimization of contemporary fears' effects.
\end{abstract}

Keywords: Criminal Law System; Punishment; Fear; Midia; Restorative Justice.

\footnotetext{
* Mestrando do PPG em Direito e Sociedade da Universidade La Salle, atuando na linha de pesquisa "Sociedade e Fragmentação do Direito" - Bolsista CAPES/PROSUC. Advogado. Membro da Comissão de Direitos Humanos da OAB Canoas/RS. Membro da Comissão Especial de Mediação e Práticas Restaurativas da OAB/RS. Email: cdaniel.souza89@gmail.com

${ }^{* *}$ Professor do Mestrado em Direito e Coordenador da Área de Direito e Política da Universidade La Salle (Brasil). Doutor em Ciências Criminais pela PUCRS (Brasil), com período de estudos na Universidade de Leuven (Bélgica). Advogado. Email: daniel.achutti@unilasalle.edu.br
}

Rev. de Formas Consensuais de Solução De Conflitos | e-ISSN: 2525-9679 | Porto Alegre | v. 4 | n. 2 | p. 13 - 27 | Jul/Dez. 2018 


\section{INTRODUÇÃO}

O presente trabalho tem como escopo o estudo da cultura do medo no Brasil, e suas principais consequências no âmbito do direito penal, a sensação de insegurança e o desejo de punição, ressaltando-se a relevância dos meios de comunicação no desencadeamento das consequências mencionadas. Posteriormente, estuda-se o desejo pela punição fragmentado em dois aspectos: (i) o desejo pelo encarceramento dos indivíduos que cometem delitos; e (ii) o desejo pelas punições ilegais.

A partir disso, o estudo se encaminha para questões relacionadas à reverência dada pela sociedade contemporânea às punições ilegais, fazendo uma análise dos estudos de Michel Foucault em sua obra Vigiar e Punir, a fim de demonstrar que houve um retrocesso na sociedade, especialmente pelo fato desses tipos de punições serem públicas e incentivarem ainda mais a autotutela.

Em seguida, abordar-se-ão aspectos que demonstram o desejo da sociedade pela pena privativa de liberdade, que é a principal resposta do sistema de justiça criminal tradicional à violência criminal no Brasil, discurso que contribui para legitimar a justiça criminal tradicional, mesmo sabendo-se que esse sistema não apresenta respostas satisfatórias à população.

Por fim, são delineadas questões relativas aos meios alternativos de resolução de conflitos na seara penal, tendo em vista a abordagem distinta que esse sistema alternativo pode apresentar à violência criminal. Para tanto, demonstra-se que a justiça restaurativa pode romper com a cultura penalizadora do país, e, portanto, minimizar a cultura do medo. Afinal, em virtude de possuir uma abordagem diversa da justiça criminal comum, principalmente pelo fato de preconizar a concepção do encontro entre os verdadeiros protagonistas do conflito, vítima e ofensor, devolvendo às partes a prerrogativa de resolverem seu conflito, e tornando o processo democrático, acredita-se que podem ser rompidos os estereótipos causados pelo sistema de justiça criminal tradicional, desconstruindo, assim, a lógica punitivista do atual modelo penal. 


\title{
2 CULTURA DO MEDO E OS MEIOS DE COMUNICAÇÃO: A SENSAÇÃO DE
} INSEGURANÇA E IMPUNIDADE PROVOCADA NO ESPECTADOR BRASILEIRO

Trabalhar sob o viés da cultura do medo ${ }^{1}$ nos remete ao pensamento de Zygmunt Bauman (2008, p. 8) segundo o qual

\begin{abstract}
O medo é mais assustador quando difuso, disperso, indistinto, desvinculado, desancorado, flutuante, sem endereço nem motivos claros; quando nos assombra sem que haja uma explicação visível quando a ameaça que devemos temer pode ser vislumbrada em toda parte, mas em lugar algum se pode vê-la. 'Medo' é o nome que damos a nossa incerteza; nossa ignorância da ameaça e do que deve ser feito - do que pode e do que não pode - para fazê-la parar ou enfrentá-la, se cessá-la estiver além de nosso alcance.
\end{abstract}

A partir disso, a propagação de mensagens midiáticas dramáticas, que alimentam o medo nas grandes metrópoles, colabora de forma determinante para a formação da sensação de impunidade e insegurança na sociedade (PASTANA, 2007, p.102). Débora Regina Pastana (2005, p. 185) aponta que matérias jornalísticas nesses moldes fazem com que a população amedrontada busque novos padrões de vida, gerando o que a autora chama de "violência defensiva".

No mesmo sentido, a autora dispõe que o medo associado à criminalidade "é hoje um assunto valorizado pela imprensa e pelas autoridades, determinando mudanças no comportamento e hábitos sociais" (PASTANA, 2005, p. 184). Nessa seara, os veículos midiáticos, nas palavras de Eugenio Rául Zaffaroni (2013, p. 197), criam “a realidade de um mundo de pessoas decentes".

É evidente, portanto, o quanto os meios de comunicação, principalmente em razão do avanço tecnológico, podem influenciar a sociedade em diferentes aspectos, tanto em questões do mercado de consumo, como em questões que dizem respeito à política criminal. Segundo Antoine Garapon (1996, p. 99),

\begin{abstract}
Os media, que são o instrumento da indignação e da cólera públicas, arriscam-se a acelerar a invasão da democracia pela emoção, a propagar um sentimento de medo e de vitimização e a reintroduzir no seio do individualismo moderno o mecanismo do bode que julgávamos reservado aos tempos passados.
\end{abstract}

\footnotetext{
1 Cultura do medo no presente trabalho, baseando-se em Pastana (2005, p. 183), "representa a somatória dos valores, comportamentos e do senso comum que, associados à questão da criminalidade, reproduz a ideia hegemônica de insegurança e, com isso, perpetua uma forma de dominação marcada pelo autoritarismo e pela rejeição aos princípios democráticos”.
} 
Além disso, como consequência do medo que é propagado nos meios de comunicação social, o desejo de punição nos dias atuais se tornou algo habitual, sobretudo em razão da sensação de insegurança, característica irrefutável da cultura do medo relacionada à violência criminal, que toma contornos inexploráveis na sociedade contemporânea. Assim,

(...) os indivíduos e as instituições moldam seus comportamentos à nova realidade e reorientam-se para conviver com o medo e a insegurança, sob a tensão e a expectativa de serem vítimas de ofensas criminais. (PASTANA, 2007, p. 96).

Ainda, é possível constatar que esse desejo de punição divide-se em dois tipos: (a) o desejo pelo encarceramento dos indivíduos que cometem delitos, sob o argumento de que o Brasil é o país da impunidade e a pena privativa de liberdade é a melhor forma de resposta à violência criminal; e (b) o desejo por punições ilegais, ou seja, o castigo "olho por olho, dente por dente", como chama Alberto Carlos Almeida (2015, p. 132).

\subsection{O desejo por punições ilegais}

Importante começar abordando o item " $b$ ", tendo em vista a necessidade de explicar alguns aspectos desse desejo de vingança que toma conta da população brasileira.

Como abordado acima, a cultura do medo tem como consequência a sensação de insegurança e impunidade. Diante disso, importante salientar que, de modo geral, a população brasileira acaba por apresentar resposta de apoio às ações policiais que resultam em mortes de pessoas, pois "a sensação de insegurança (...) motiva os indivíduos a apoiarem qualquer solução para o crime, mesmo que seja no estilo 'olho por olho, dente por dente"' (ALMEIDA, 2015, p. 132-132). Alberto Carlos Almeida (2015, p. 132) destaca que as punições ilegais desse tipo possuem diversas modalidades - linchamentos, contratação de grupos de extermínio ou de pistoleiros, assassinato de bandidos que se entregam pacificamente, além do estupro de estupradores, ladrões espancados em praça pública, dentre outras -, e uma enorme proporção de brasileiros concorda com elas. 
Nesse aspecto, inevitável rememorar os dispositivos disciplinares ${ }^{2}$ mencionados por Michel Foucault em Vigiar e Punir ${ }^{3}$, os quais correspondem ao conjunto de técnicas e procedimentos com a finalidade de "produzir corpos politicamente dóceis e economicamente rentáveis" (CASTRO, 2015, p. 86), oportunidade em que o autor demonstra o processo de transformação das formas de castigo entre 1757 e 1838. Como afirma Edgardo Castro (2015, p. 87) ocorre

(...) a desaparição do espetáculo punitivo, pois a pena se vai a deslocar da intensidade visível do sofrimento à consciência abstrata da certeza de ser castigado, e uma modificação maior na finalidade explícita do sistema judicial que, em lugar de castigar, agora diz que busca corrigir e curar.

Conforme Foucault, o corpo deixou de ser alvo principal da repressão penal, e a punição de ser um espetáculo, motivo pelo qual "a justiça não mais assume publicamente a parte de violência que está ligada ao seu exercício”(FOUCAULT, 2014, p.14).

Seguindo esta linha de raciocínio, verifica-se um deslocamento do alvo da punição: antes, o castigo visava ao sofrimento do corpo da forma mais cruel e pelo maior tempo possível. A partir de então, a punição passa a incidir sobre a "alma" do condenado, de modo a

Não tocar mais o corpo, ou o mínimo possível, e para atingir nele algo que não é o corpo propriamente. Dir-se-á: a prisão, reclusão, os trabalhos forçados, a servidão de

2 Conforme explica Judith Revel (2005, p. 35) disciplina para Michel Foucault é uma "modalidade de aplicação do poder que aparece entre o final do século XVIII e o início do século XIX. O 'Regime Disciplinar' caracteriza-se por um certo número de técnicas de coerção que exercem um esquadrinhamento sistemático do tempo, do espaço e do movimento dos indivíduos e que atingem particularmente as atitudes, os gestos, os corpos: 'Técnicas de individualização do poder. Como vigiar alguém, como controlar sua conduta, seu comportamento, suas atitudes, como intensificar sua performance, multiplicar suas capacidades, como colocálo no lugar onde ele será útil'. O discurso da disciplina é estranho à lei ou a regra jurídica derivada de soberania: ela produz um discurso sobre a regra natural, isto é, sobre a norma". No que tange aos dispositivos a autora (REVEL, 2005, p. 39) dispõe que "o termo dispositivo aparece em Foucault nos anos 70 e designa inicialmente os operadores materiais do poder, isto é, as técnicas, as estratégias e as formas de assujeitamento utilizadas pelo poder".

3 Para Johanna Oksala (2011, p. 75) “em Vigiar e Punir Foucault analisa as maneiras como sujeitos criminosos - indivíduos que são entendidos e entendem a si mesmos como delinquentes - são constituídos em redes de poder/saber. Em primeiro lugar, as práticas na prisão manipulam e moldam concretamente seus corpos através de regimes de exercício, regras minuciosamente detalhadas, vigilância constante, dieta e horários estritos. Hábitos e padrões de comportamento são destruídos e reconstruídos de novas maneiras. Em segundo lugar, os corpos dos prisioneiros são classificados e examinados cientificamente. Embora as tipologias dos primórdios da criminologia possam ter sido descartadas, os princípios de observação e avaliação prevaleceram. Os prisioneiros são casos a ser estudados cientificamente, bem como corrigidos institucionalmente. (...)Vigiar $e$ Punir exemplifica poderosamente as características essenciais de uma crítica genealógica. Tem a forma de um estudo histórico detalhado, documentando o desenvolvimento das instituições carcerárias modernas desde as masmorras e os espetáculos públicos de tortura que as precederam. Questiona a inevitabilidade desse desenvolvimento, mostrando sua contingência histórica, bem como as contradições internas no funcionamento das prisões modernas." 
forçados, a interdição de domicílio, a deportação - que parte tão importante tiveram nos sistemas penais modernos - são penas 'físicas': com exceção da multa, se referem diretamente ao corpo. (...) O corpo se encontra aí em posição de instrumento ou intermediário; qualquer intervenção sobre ele pelo enclausuramento, pelo trabalho obrigatório visa privar o indivíduo de sua liberdade considerada ao mesmo tempo como um direito e como um bem (FOUCAULT, 2014, p.15).

Todavia, o que se percebe hoje é que as punições ao estilo "olho por olho dente por dente" voltaram a ser exaltadas, principalmente se ocorridas em local público ou nas redes sociais. Compreende-se, então, um retrocesso quanto às formas de castigo e sua percepção pelo grupo social, a partir da constatação de que as punições ilegais voltaram a ser celebradas por parte da sociedade contemporânea.

É possível concluir, portanto, que "a defesa das punições ilegais está relacionada a fatores como o medo de ser vítima de algum tipo de violência, ao fato de já ter sido vítima, ou mesmo à avaliação e à confiança que se tem na polícia" (ALMEIDA, 2015, p. 140), em consequência da confiabilidade depositada nas instituições. Como exalta Leandro Ayres França (2012, p. 316) "a nossa segurança depende do controle deles".

Logo, o suplício que ocorreu até a metade do século XVIII volta a ser visto por parte da população como prática necessária no combate à criminalidade, o que leva a crer que pode ser uma consequência - direta ou indireta - da cultura do medo disseminada no país.

\subsection{O desejo pelo encarceramento a todo custo}

No que tange ao item “ $a$ ” - o desejo da população pelo encarceramento dos indivíduos criminosos sob o argumento de que o Brasil é o país da impunidade e a pena privativa de liberdade é a melhor forma de resposta à violência -, esse tipo de manifestação deve ser refutado na sua integralidade, uma vez que, por exemplo, o Brasil possui a terceira maior população carcerária do mundo, conforme o último Levantamento Nacional de Informações Penitenciárias - INFOPEN ${ }^{4}$.

O relatório demonstra que a população carcerária brasileira possui 726.712 detentos, atrás apenas dos Estados Unidos, com 2.145.100 presos, e da China, com 1.649.804 encarcerados. Atualmente, faltam 358.663 vagas para presos nos presídios brasileiros: com apenas 368.048 lugares disponíveis, a taxa de ocupação chega a 197,4\%.

$4 \quad$ BRASIL, 2017. 
Segundo Débora Pastana (2007, p. 102) “a notícia sobre violência começou a não só informar como a emocionar, estimulando a curiosidade, a intolerância e, por fim, o próprio medo". Sendo assim, o reflexo da veiculação das notícias realizadas pelos meios de comunicação na sociedade brasileira, além de maximizar a cultura do medo no país, trouxe um retrocesso enorme à sociedade quanto ao senso de justiça, pois além da intolerância com o ofensor, acaba por aceitar que o sistema penal por meio do discurso de que a pena privativa de liberdade é a melhor solução à violência criminal. Essa forma de ver a questão acabou reforçando o sentimento individualista e, sobretudo, a segregação e discriminação no país (PASTANA, 2007), sobretudo em razão do sistema penal se dirigir "quase sempre contra certas pessoas, mais do que certas ações legalmente definidas como crime", a partir da constatação de que a clientela do sistema penal é composta "regularmente em todos os lugares do mundo por pessoas pertencentes aos baixos estratos sociais", ficando evidente "que há um processo de seleção de pessoas às quais se qualifica como delinquentes e, não, como se pretende, um mero processo de seleção de condutas qualificadas como tais" (ANDRADE, 2015, p. 266).

Nesse sentido, importante demonstrar o perfil da clientela do sistema de justiça criminal no Brasil, que se caracteriza da seguinte forma:

(1) Quanto à faixa etária dos apenados: 30\% possuem de 18 a 24 anos de idade; 25\%, de 25 a 29 anos de idade; 19\%, entre 30 a 34 anos; 19\%, entre 35 a 45 anos; 7\%, de 46 a 60 anos; $1 \%$, de 61 a 70 anos;

(2) Quanto à raça, cor ou etnia: 64\% da população carcerária é composta por negros; $35 \%$, brancos; $1 \%$, amarela, indígena e outras; e

(3) Quanto à escolaridade: 4\% são analfabetos; 6\%, alfabetizados sem cursos regulares; $51 \%$ não concluíram o ensino fundamental; $14 \%$ possuem o ensino fundamental completo; $15 \%$ não concluíram o ensino médio; $9 \%$ possuem o ensino médio completo; e $1 \%$ possui o ensino superior incompleto. ${ }^{5}$

Partindo-se da premissa de que o principal propósito da pena privativa de liberdade é reeducar o indivíduo para que retorne à convivência em sociedade, verifica-se sem dificuldade que tal finalidade não é alcançada. Mudar a concepção sobre como lidar com os conflitos criminais no país torna-se prioridade, pois os meios alternativos de resolução de conflitos, em especial a justiça restaurativa, podem trazer respostas bastante diversas das tradicionalmente percebidas no sistema de justiça criminal tradicional.

5 Para acesso as informações complementares, verificar Relatório INFOPEN (BRASIL, 2017). 


\section{OS MEIOS ALTERNATIVOS DE RESOLUÇÃO DE CONFLITOS NA SEARA PENAL E A POSSIBILIDADE DE MINIMIZAÇÃO DOS EFEITOS DA CULTURA DO MEDO}

Abordar questões relacionadas ao Direito Penal e ao Processo Penal no Brasil tem sido um grande desafio para os juristas e para o meio acadêmico, principalmente quando os meios de comunicação utilizam a sensação de impunidade e a insegurança no país como mercadoria, "criando a realidade de um mundo de pessoas decentes" (ZAFFARONI, 2013, p. 197) e, por outro lado, de indecentes, o que acaba por alimentar o discurso do senso comum de que o Brasil seria o país da impunidade (PASTANA, 2005). Muito embora, como facilmente se percebe, os dados do grande encarceramento brasileiro demonstrem a fragilidade desse discurso.

Pode-se dizer, desse modo, que o fracasso do sistema de justiça criminal tradicional, principalmente pela falta de respostas efetivas à violência criminal, aumenta as sensações de insegurança e impunidade, e colabora para a propagação da cultura do medo. Além do mais, o Estado não apresenta alternativas para lidar com conflitos criminais e diminuir os índices de violência, o que continua a legitimar esse sistema fracassado, muito embora os dados estatísticos apresentem respostas contrárias às esperadas.

Exemplo disso são percebidos dados divulgados pela Secretaria de Segurança Pública do Estado do Rio Grande do Sul ${ }^{6}$ : no ano de 2015 foram registrados 2.431 homicídios dolosos, ao passo que no ano de 2016 houve 2.608 registros para o mesmo delito, ou seja, houve um aumento de $4 \%$ de um ano para o outro, como se pode observar no gráfico abaixo.

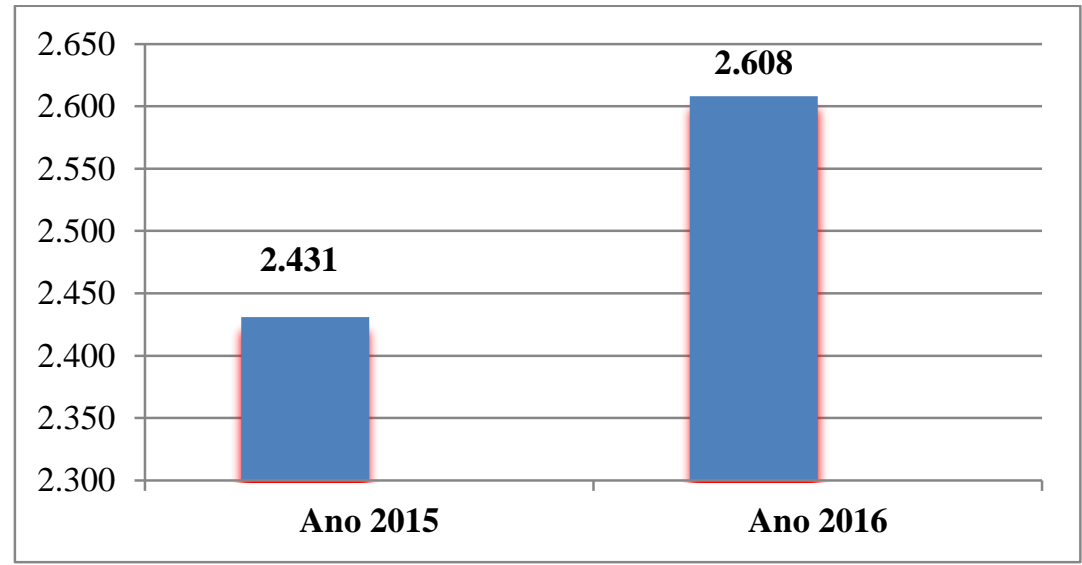

6 Secretaria de Segurança Pública do Estado do Rio Grande do Sul. Indicadores Criminais. Disponível em: http://www.ssp.rs.gov.br/indicadores-criminais. Acesso em: 18 de dezembro de 2017. 
Gráfico n. 1 - Homicídios dolosos registrados no RS nos anos de 2015 e 2016.

Nesse sentido, pode-se concluir que o sistema de justiça criminal tradicional não apresenta respostas efetivas ao problema do crime, pois, mesmo com o encarceramento em massa que caracteriza atualmente o país, os índices de violência não apresentam diminuição. Como reflexo disso, a opinião pública e dos órgãos de controle acaba sempre por legitimar esse sistema falido (PASTANA, 2007), e também pode-se ressaltar pelo fato de não existir outra forma de lidar com conflitos criminais no Brasil.

Para Louk Hulsman (1993, p. 55),

\begin{abstract}
Ao tratarem dos problemas da justiça penal, os discursos políticos, grande parte da mídia e alguns estudiosos da política criminal se põem de acordo e dão a palavra a um determinado "homem comum". Este homem comum seria obtuso, covarde e vingativo. Não faria distinção entre os marginais, os violentos, os molestadores de todos os tipos, reservando-lhes em bloco o desprezo público. Imaginaria as prisões cheias de perigosos assassinos. E veria o aparelho penal o único meio de proteção contra os fenômenos sociais que o perturbam. Ora, este homem comum não existe! Trata-se de uma cômoda abstração para legitimar o sistema existente e reforçar suas práticas.
\end{abstract}

Por isso, diante da constatação da séria crise de legitimidade e eficiência que atravessa o sistema de justiça criminal tradicional (ZAFFARONI, 2001), bem como dos substitutivos penais, a análise de um sistema alternativo de resolução de conflitos na seara penal, especificamente a justiça restaurativa, deve ser priorizada. Parte-se, portanto, do pressuposto de que a justiça restaurativa, enquanto tal, pode instituir um meio democrático para resolução dos conflitos em virtude da participação direta dos envolvidos no caso e daqueles que se sentirem lesados pelo ato delituoso.

Pensar nos meios alternativos de resolução de conflitos na seara penal pode ser uma alternativa para o rompimento do pensamento impregnado na sociedade de que a justiça penal é única alternativa para lidar com o problema da violência criminal, principalmente se tratando da justiça restaurativa. Achutti e Pallamolla (2017, p. 438) destacam que a justiça restaurativa “(...) antes de ser considerada uma ideia fechada e acabada, trata-se, primordialmente, de uma proposta conceitual que continua aberta".

A justiça restaurativa, amparada por princípios e valores ${ }^{7}$, possui uma abordagem bastante diversa da justiça retributiva: “a justiça retributiva postula que a dor é o elemento capaz

7 Conforme Achutti (2014, p. 68) os valores restaurativos são divididos em três grupos: (i) valores obrigatórios: esse grupo de valores cuja inobservância pode comprometer de forma severa o caráter restaurativo dos 
de acertar as contas, mas na prática ela vem se mostrando contraproducente, tanto para a vítima quanto para o ofensor” (ZEHR, 2015, p. 82). Já a justiça restaurativa, por sua vez, acaba por sustentar que o elemento competente para resolver a situação problema é o "reconhecimento dos danos sofridos pela vítima e suas necessidades com o esforço ativo para estimular o ofensor a assumir a responsabilidade, corrigir os males e tratar as causas daquele comportamento" (ZEHR, 2015, p. 82).

Nessa lógica, pode-se apontar as seguintes diferenças entre justiça restaurativa e justiça criminal tradicional: (a) na justiça tradicional o crime é uma violação da lei e do Estado, ao passo que na justiça restaurativa o crime é uma violação de pessoas e de relacionamentos; (b) para justiça criminal as violações geral culpa, já na justiça restaurativa as violações geram obrigações; (c) o sistema de justiça criminal tradicional exige que o Estado determine a culpa e imponha uma punição (sofrimento), diferente da justiça restaurativa que envolve vítimas, ofensores e membros da comunidade num esforço comum para reparar os danos; e (d) o foco central da justiça criminal é que os ofensores devem receber o que merecem totalmente diverso da justiça restaurativa, que preconiza as necessidades da vítima e a responsabilidade do ofensor de reparar o dano cometido (ZEHR, 2015, p. 37).

Ulf Christian Eiras Nordenstahl (2005, 33), por sua vez, completa:

\begin{abstract}
El sistema tradicional evoca el procedimiento adversarial, modelo impuesto desde los mismos programas de estúdio de formación profesional universitaria de derecho y para el que está preparado todo el sistema judicial. Académicamente aún es resistida la introducción en la currícula de materias afines a los métodos alternativos, a las que se les assigna menor puntaje o carga horaria. Por el contrario, el modelo restaurativo deja de lado el método adversarial y busca uma solución acordada en um ámbito propicio para el diálogo, proceso éste conducido por un operador (llámase mediador, conciliador o facilitador) que tiene a su cargo el trabajo de promover la comunicación entre las partes a través de la aplicación de técnicas y dinâmicas adecuadas.
\end{abstract}

encontros, é formado por valores impositivos - não dominação, empoderamento, respeito aos limites, escuta respeitosa, igualdade de preocupação pelos participates, accountability/ appealability e respeito aos direitos previstos na Declaração Universal de Direitos Humanos e na Declaração de Princípios Básicos da justiça para as vítimas de crime de abuso de poder, assim como àqueles previstos em outros tratados e acordos internacionais - que tem como finalidade prevenir que o processo se torne opressivo; (ii) valores encorajados: que são os valores orientadores do procedimento; e (iii) aqueles que podem ser considerados como o resultado de um encontro bem-sucedido, mas que não devem ser solicitados ou exigidos pelo mediador ou qualquer das partes. Já no que concerne aos princípios da justiça restaurativa, o autor (ACHUTTI, 2014, p. 72) refere que não se trata de um catálogo de princípios de obrigatória observação, mas de um guia geral relacionado ao tema, que pode ou não ser adotado pelos Estados-membros que desejam implementar a justiça restaurativa em seus países. 
Também, importante referir que, conforme Raffaella Pallamolla (2009), a justiça restaurativa possui três concepções: a concepção do encontro; a concepção da reparação; e a concepção da transformação. Para a autora, a concepção do encontro

(...) é que a melhor expressa uma das ideias centrais do movimento, ao afirmar que vítima, ofensor e outros interessados no caso devem ter a oportunidade de encontrarse em um local não tão informal e dominado por especialistas (advogados e juízes, por exemplo) como fóruns e tribunais. (PALLAMOLLA, 2009, p. 55).

Diante disso, a concepção do encontro contribui para o tema aqui abordado, em vista da possibilidade de contribuição para a ruptura do medo criado em torno do estigmatizado ${ }^{8}$ pela sociedade e pelo processo criminal: o ofensor.

Nessa esteira, é possível dizer que a concepção do encontro proporciona que os envolvidos no conflito "abandonem a passividade e assumam posições ativas nas discussões e na tomada de decisões sobre o que deve ser feito com relação ao delito, sempre com a ajuda de um facilitador" (PALLAMOLLA, 2009, p. 55). A partir disso, refere Daniel Achutti (2014) que o envolvimento direto das partes viabiliza a construção de um processo democrático, com a participação ativa das partes por meio do diálogo, com a finalidade de atingir seus anseios e superar seus medos e dificuldades oriundas do conflito criminal.

Para Pallamolla e Achutti (2017a, p. 281)

(...) uma das vantagens da aplicação da justiça restaurativa frequentemente apontada é a constatação de resultados positivos com respeito à vitima, ao delinquente e à comunidade, relacionados com a maior flexibilidade do processo e de intervenção das partes, destacando estudos de campo de alto nível de satisfação por parte da vítima e do autor do delito com a mediação e, em geral, com a administração pública.

8 Louk Hulsman (1993, p. 69) aduz que "o sentimento de culpa interior que às vezes se invoca para justificar o sistema penal - o autor de um crime teria necessidade do castigo - nada tem a ver com a existência de tal sistema. Não se trata de negar que os homens possam experimentar uma profunda perturbação a propósito de alguns de seus atos ou comportamentos. Mas, é preciso afirmar com toda a convicção que não é a existência do sistema penal que provoca tal sentimento, tanto quanto não é este sistema que poderá dar àquele que sofre, com sua consciência, a transformação interior de que possa necessitar. Nossas experiências profundas nada têm a ver com o sistema penal. Ao contrário, é preciso denunciar as culpabilizações artificiais que este sistema produz. Em inúmeros casos, a experiência do processo e do encarceramento produz nos condenados um estigma que pode se tornar profundo. Há estudos científicos, sérios e reiterados, mostrando que as definições legais e a rejeição social por elas produzida podem determinar a percepção do eu como realmente 'desviante' e, assim, levar algumas pessoas a viver conforme esta imagem, marginalmente. Nos vemos de novo diante da constatação de que o sistema penal cria o delinquente, mas, agora, num nível muito mais inquietante e grave: o nível da interiorização pela pessoa atingida do etiquetamento legal e social." 
Desse modo, a justiça restaurativa, enquanto meio alternativo de resolução de conflitos na seara penal, pode trazer significativas mudanças para a administração de conflitos criminais, particularmente em questões relacionadas ao estereótipo do acusado. Com o convencimento formado pelos meios de comunicação e marcadas pelo senso de justiça imposto pelo Estado de que o sistema de justiça criminal tradicional é a melhor saída para solução da violência criminal - as partes acabam por esquecer a particularidade de seus conflitos, sobretudo as vítimas, que atualmente figuram como mero objeto de prestação de depoimentos no decorrer do processo penal ${ }^{9}$ (GIAMBERARDINO, 2015). As vítimas não percebem, na maioria das vezes, que resolver os conflitos criminais pela via tradicional não traz uma solução efetiva para o seu problema.

Para Ulf Christian Eiras Nordenstahl (2008, p. 59)

\begin{abstract}
La víctima puede tener la intención de participar en el proceso, de ser un protagonista y no un actor de reparto. Tal como ya lo adelantáramos, durante mucho tempo se le ha negado esa posibilidad. La Asunción por parte del Estado de la representación de los intereses del lesionado juridicamente impedió que el verdadero damnificado se sintiera parte. Dentro del procedimento penal se ha empujado a la víctima cada vez más a la periferia del Derecho Procesal Penal, en donde le queda solamente el rol de mero objeto de procedimiento.
\end{abstract}

Colocar as partes no mesmo nível hierárquico - na atual estrutura do processo penal, as partes são representadas por advogados e o juiz detém o monopólio de proferir a decisão sobre o caso - pode romper com o senso comum de que a pena privativa de liberdade é a melhor saída em casos criminais, e, principalmente, demonstrar de como a cultura do medo tem direta influência na percepção de que resolver os conflitos por meio do sistema de justiça criminal tradicional é mais eficiente.

\title{
4 CONSIDERAÇÕES FINAIS
}

Pode-se concluir, portanto, que a cultura do medo propagada no país pelos meios de comunicação acaba colaborando para o estabelecimento de um importante retrocesso social. Primeiro, por conta do discurso de que o Brasil é o país da impunidade, e segundo por possibilitar que as punições ilegais sejam reverenciadas pela população.

9 Conferir: André Ribeiro Giamberardino, 2018. 
Por esse motivo, torna-se relevante abordar os meios alternativos de resolução de conflitos na seara penal. Não só por ser um sistema que possui uma abordagem bastante diversa da justiça criminal convencional, mas, principalmente, pelo fato de trazer a possibilidade de ruptura com a cultura medo: uma vez que a justiça restaurativa procura reintegrar, reparar e responsabilizar os envolvidos pelos seus atos, pode-se projetar um novo modo de perceber as pessoas envolvidas em conflitos, sejam eles criminais ou não. Inclusive, importante mencionar que está em curso uma expansão da justiça restaurativa no âmbito do Poder Judiciário brasileiro (PALLAMOLLA; ACHUTTI, 2017b).

Ademais, passa a ser possível uma mudança na percepção quanto ao senso de justiça, tradicionalmente vinculado ao encarceramento e à pena privativa de liberdade, o que possibilita deixar de lado "o caráter elitista do direito em sua concepção e práticas hegemônicas e o seu papel como mecanismo de dominação de classes, de diferenciação, hierarquização e exclusão social" (SANTOS, 2011, p. 113).

Portanto, abordar a questão da violência criminal por meio da justiça restaurativa pode colaborar de forma significativa para o rompimento da cultura do medo no país, justamente pelo fato desse sistema reaproximar os envolvidos, afastando os estigmas e por construir uma justiça democrática despida de preconceitos e discriminações. Rompe-se, igualmente, com a ficção criada pela mídia de massa, constrói representações sociais sobre o fenômeno criminal, com intuito financeiro, de modo a torna-lo um produto para venda e consumo em massa, pautado pelo sensacionalismo e, consequentemente, pela perspectiva da criação de verdadeiros espetáculos (FRANÇA, 2012).

Além do mais, pode-se dizer que a implementação dos meios alternativos na seara penal é o primeiro passo para transformação da cultura punitivista em um algo menos repressivo, que possui enorme potencial para colaborar para a desconstrução da imagem estranhamente positiva formada pelo senso comum a respeito da justiça criminal tradicional - o que, há muito se sabe, não encontra qualquer correspondência com a realidade (BARATTA, 2011).

Desse modo, abordar questões relacionadas à cultura do medo significa colocar em discussão o sistema de justiça criminal tradicional, pois não se trata de não fazer justiça, mas, sim, sobre como ela é produzida. Mudar essa convicção é o ponto de partida para que um novo caminho comece a ser construído, por meio de uma justiça em que os verdadeiros protagonistas do conflito possam ser protagonistas, e não meros coadjuvantes, do processo de deliberação sobre o que deve ser feito com os seus próprios conflitos, em especial aqueles legalmente classificados como criminais. 


\section{REFERÊNCIAS}

ACHUTTI, Daniel. Justiça Restaurativa e abolicionismo penal: contribuições para um novo modelo de administração de conflitos no Brasil. 1. ed. São Paulo: Saraiva, 2014.

ACHUTTI, Daniel; PALLAMOLLA, Raffaella da Porciuncula. Justiça restaurativa. In: LIMA, Renato Sérgio de; RATTON, José Luiz; AZEVEDO, Rodrigo Ghiringhelli de (Org.). Crime, polícia e justiça no Brasil. São Paulo: Contexto, 2014, p. 436-449.

ALMEIDA, Carlos Alberto. A cabeça do brasileiro. 8 ed. Rio de Janeiro: Record, 2015.

ANDRADE, Vera Regina Pereira de. A ilusão de segurança jurídica: do controle da violência à violência do controle penal. 3. ed. Porto Alegre: Livraria do Advogado, 2015.

BARATTA, Alessandro. Criminologia crítica e crítica do Direito Penal: introdução à sociologia do direito penal. trad. Juarez Cirino dos Santos. 6 ed. Rio de Janeiro: Revan, 2011.

BAUMAN, Zygmunt. Medo líquido. trad. Carlos Alberto Medeiros. Rio de Janeiro: Zahar, 2008.

BONACCORSI, Daniela Villani; CAMARGO, Júlia Lio Rocha. Justiça Restaurativa: participação ou impunidade? In: VALOIS, Luiz Carlos; SANTANA, Selma; MATOS, Taysa; ESPIÑEIRA, Bruno (orgs.). Justiça restaurativa. Belo Horizonte: Editora D’Plácito, 2017. p. 465-482.

BRASIL. Ministério da Justiça. Departamento Penitenciário Nacional. Levantamento Nacional de Informações Penitenciárias INFOPEN. 2017. Disponível em: http://www.justica.gov.br/noticias/ha-726-712-pessoas-presas-no-

brasil/relatorio_2016_junho.pdf. Acesso em: 16 de dezembro de 2017.

CASTRO, Edgardo. Introdução a Foucault. 1 ed. trad. Beatriz de Almeida Magalhães. Belo Horizonte: Autêntica Editora, 2015.

EIRAS NORDENSTAHL, Ulf Christian. ¿Dónde está la víctima?: apuntes sobre victimologia. Buenos Aires: Libreria Histórica, 2008.

. Mediación penal: de la práctica a la teoría. Buenos Aires: Librería Histórica, 2005.

FRANÇA, Leandro Ayres. Inimigo ou a inconveniência de existir. Rio de Janeiro: Lumen Juris, 2012.

FOUCAULT, Michel. Vigiar e punir: nascimento da prisão. 42 ed. trad. Raquel Ramalhete. Rio de Janeiro: Vozes, 2014.

GARAPON, Antonie. O guardador de promessas: justiça e democracia. trad. Francisco Aragão. Lisboa: Instituto Piaget, 1996.

GIAMBERARDINO, André Ribeiro. Crítica da pena e justiça restaurativa: a censura para além da punição. 1 ed. Florianópolis: Empório do Direito Editora, 2015.

Rev. de Formas Consensuais de Solução De Conflitos | e-ISSN: 2525-9679 | Porto Alegre | v. 4 | n. 2 | p. 13 - 27 | Jul/Dez. 2018 
O confisco do conflito na historiografia penal. Revista Eletrônica Direito e

Sociedade, Canoas, v. 6, n. 2, Ahead of print, agosto. 2018.

HULSMAN, Louk; CELIS, Jacqueline Bernat de. Penas perdidas: o sistema penal em questão. 1 ed. Trad. Maria Lúcia Karam. Rio de Janeiro: Laum, 1993.

OKSALA, Johanna. Como ler Foucault. trad. Maria Luiza X. de A. Borges. Rio de Janeiro: Zahar, 2011.

PASTANA, Débora Regina. Cultura do medo e democracia: um paradoxo brasileiro. Mediações, Londrina, v. 10, n. 2, jul./dez. 2005. Disponível em: <http://www.uel.br/revistas/uel/index.php/mediacoes/article/view/2172/1864>. Acesso em: 14 nov. 2017.

PASTANA, Débora Regina. Medo e opinião pública no Brasil contemporâneo. Estudos de Sociologia, Araraquara, v.12, n.22, p.91-116, 2007.

PALLAMOLLA, Raffaella da Porciuncula. Justiça restaurativa: da teoria à pratica. São Paulo: IBCCRIM, 2009.

PALLAMOLLA, Raffaella; ACHUTTI, Daniel. Justiça criminal e justiça restaurativa: possibilidades de ruptura com a lógica burocrático-retribucionista. In: VALOIS, Luiz Carlos; SANTANA, Selma; MATOS, Taysa; ESPIÑEIRA, Bruno (Org.). Justiça restaurativa. Belo Horizonte: D'Plácido, 2017a, p. 265-283.

PALLAMOLLA, Raffaella; ACHUTTI, Daniel. Levando a justiça restaurativa à sério: análise crítica de julgados do Tribunal de Justiça do Estado do Rio Grande do Sul. Revista Eletrônica Direito e Sociedade, Canoas, v. 5, n. 2, p. 279-289, nov. 2017 b.

REVEL, Judith. Foucault: conceitos essenciais. trad. Maria do Rosário Gregolin, Nilton Milanez, Carlos Piovesani. São Carlos: Claraluz, 2005.

SANTOS, Boaventura de Sousa. Para uma revolução democrática da justiça. 3 ed. São Paulo: Editora Cortez, 2011.

SICA, Leonardo. Justiça Restaurativa e Mediação Penal. O novo modelo de justiça criminal e de gestão do crime. Rio de Janeiro: Editora Lumen Juris, 2007.

ZAFFARONI, Eugênio Raúl. Em busca das penas perdidas: a perda de legitimidade do sistema penal. 5. ed. Trad. Vania Romano Pedrosa, Amir Lopez da Conceição. Rio de Janeiro: Revan, 2001.

ZAFFARONI, Eugenio Raúl. A questão criminal. Trad. Sérgio Lamarão. 1. ed. Rio de Janeiro: Revan, 2013.

ZEHR, Howard. Justiça Restaurativa. 2 ed. trad. Tônia Van Acker. São Paulo: Palas Athena, 2015. 